\title{
HOT CORROSION RESISTANT AND HIGH STRENGTH NICKEL-BASED SINGLE CRYSTAL AND DIRECTIONALLY-SOLIDIFIED SUPERALLOYS DEVELOPED BY THE d-ELECTRONS CONCEPT
}

\author{
Y.Murata $^{1)}$, S. Miyazaki ${ }^{2)}$, M.Morinaga $^{1}$ and R.Hashizume ${ }^{3 \text { ( }}$ \\ 1) Department of Materials Science and Engineering, School of Engineering, \\ Nagoya University, Furo-cho, Chikusa-ku, Nagoya 464-01, JAPAN \\ 2) Graduate School of Toyohashi University of Technology, (Present address: SMC Corp. \\ Ltd., 4-2-2, Kinunodai, Yawara-mura, Tukuba-gun, Ibaraki 300-24, JAPAN) \\ 3) Materials Research Section, Technical Research Center, The Kansai Electric \\ Power Company, Inc., 11-20 Nakoji 3-chome, Amagasaki 661, JAPAN
}

\begin{abstract}
New nickel-based superalloys for industrial turbines with high $\mathrm{Cr}$ content were designed with the aid of the d-electrons concept. This concept has been developed on the basis of the molecular orbital calculations of the electronic structures of $\mathrm{Ni}$ alloys. Two electronic parameters are important in this concept. One is the bond order between an alloying element and nickel atoms, Bo, and the other is the d-orbital energy level of alloying element, Md. Employing these parameters, singlecrystal(SC) superalloys were designed with the compositions : $\mathrm{Ni}-(9.5 \sim 12.0) \mathrm{Al}-(16.5 \sim 18.0) \mathrm{Cr}-$ (0.6 2.4)Ti-(0.3 1.8)Ta-(0 0.5)Nb-(0.9 1.6)W-(1.2 1.8 Mo-(0 0.25)Re [mol\%]. A similar method was also employed for the design of directionally solidified(DS) alloys. Namely, alloy compositions without any grainboundary strengthening elements were firstly designed and then a small amount of Hf was simply added into them to strengthen the grain-boundaries. The creep properties and hot corrosion resistance were evaluated experimentally for these SC and DS alloys. As a result, the SC alloys were found to be superior in the creep rupture life to a reference alloy, SC-16, while keeping hot corrosion resistance as high as SC-16 and IN738LC. The DS alloys also exhibited better creep properties than several alloys so far developed.
\end{abstract}

\section{Introduction}

There is a great demand for advanced nickel-based superalloys, mainly for the application to industrial gasturbine blades. They should possess an excellent combination of hot corrosion resistance and hightemperature strength. Despite the recent innovation of coating technology, hot corrosion resistance is still important for industrial turbines which are for a long term service.

Superior nickel-based single-crystal superalloys (TUT alloys) for aircraft turbines [1,2] have been developed successfully with the aid of the d-electrons concept. This concept has been devised on the basis of the molecular orbital calculations of electronic structures [3]. Two electronic parameters are utilized mainly for the alloy design following this concept. One is the bond order between an alloying element and nickel atoms (hereafter referred to as Bo), and the other is the d-orbital energy level of alloying element (referred to as $\mathrm{Md}$ ). The values of Bo and Md are listed in Table 1 for each element in nickel-based superalloys. For simplicity, the units of $\mathrm{Md}, \mathrm{eV}$, are omitted in the following sections of this paper. For an alloy, the averaged values of Bo and $\mathrm{Md}$ are defined by taking the compositional average, and $\overline{B o}$ and $\overline{M d}$ are denoted as follows:

$$
\begin{aligned}
& \overline{\mathrm{Bo}}=\Sigma \mathrm{X}_{\mathrm{i}}(\mathrm{Bo})_{\mathrm{i}}, \\
& \overline{\mathrm{Md}}=\Sigma \mathrm{X}_{\mathrm{i}}(\mathrm{Md})_{\mathrm{i}} .
\end{aligned}
$$

Here, $X_{i}$ is the atomic fraction of component $i$ in the alloy, $(\mathrm{Bo})_{i}$ and $(\mathrm{Md})_{\mathrm{i}}$ are the $\mathrm{Bo}$ and $\mathrm{Md}$ values for component $i$, respectively.

The usefulness and the validity of the Bo-Md diagram has been proved for the prediction of alloy properties. A target region for alloy design has been specified on the diagram in a concrete way, as explained later $[4,5]$.

Generally it is known that in order to increase hotcorrosion resistance, $\mathrm{Cr}$ content in the alloy should be

\begin{tabular}{|c|c|c|c|c|c|c|}
\hline Element & $\mathrm{Md}(\mathrm{eV})$ & Bo & \multicolumn{2}{|c|}{ Element } & $\operatorname{Md}(e V)$ & Bo \\
\hline \multirow{5}{*}{$\begin{array}{ll} & \mathrm{Ti} \\
\mathrm{V} \\
\mathrm{Cr} \\
\text { 3d } \mathrm{Mn}\end{array}$} & \multirow{5}{*}{$\begin{array}{l}2.271 \\
1.543 \\
1.142 \\
0.957\end{array}$} & \multirow[b]{2}{*}{1.098} & \multirow{3}{*}{$4 d$} & $\mathrm{Z}$ & 0 & 1.479 \\
\hline & & & & 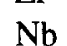 & 2.1 & 1.59 \\
\hline & & 1.141 & & Mo & 1.550 & 1.611 \\
\hline & & 1.278 & \multirow{4}{*}{$5 d$} & & & \\
\hline & & 1.001 & & T & & $\gamma$ \\
\hline $\mathrm{Fe}$ & 0.858 & 0.857 & & $\mathrm{w}$ & 1655 & 173 \\
\hline $\begin{array}{l}\mathrm{Co} \\
\mathrm{Ni}\end{array}$ & $\mid \begin{array}{l}0.777 \\
0.717\end{array}$ & $\begin{array}{l}0.697 \\
0.514\end{array}$ & & $\mathrm{Re}$ & 1.267 & 1.692 \\
\hline \multirow[t]{2}{*}{$\mathrm{Cu}$} & 0.615 & 0.272 & \multirow{2}{*}{\multicolumn{2}{|c|}{ Others $\begin{array}{l}\mathrm{Al} \\
\mathrm{Si}\end{array}$}} & 1000 & 33 \\
\hline & & & & & & 0.58 \\
\hline
\end{tabular}

Table 1. List of Md and Bo values for various elements. 
higher than $10 \mathrm{~mol} \%$. The purpose of this study is to design single-crystal superalloys and directionally solidified superalloys both of which contain more than $10 \mathrm{~mol} \% \mathrm{Cr}$ and possess an excellent combination of hotcorrosion resistance and creep-rupture life. For this design, the d-electrons concept has been employed to save time and cost for alloy development.

\section{d-Electrons Concept}

\section{Target Region for Alloy Design}

As shown in Fig.1 and Fig.2, it is interesting to note here that high performance nickel-based superalloys are located on a very small region in the Bo- Ma diagram. For example, as shown in Fig.1, the high temperature $0.2 \%$ yield stress of conventionally cast superalloys shows a maximum near the position of 0.67 for $\overline{B o}$ and 0.98 for Md. Also, as shown in Fig.2, the 100hrs creep-rupture strength at $1255 \mathrm{~K}$ shows a maximum near this position. In addition, single crystal superalloys are located in the shadowed region near this position as shown in Fig. 1 and Fig.2. Thus, there is definitely a target region for the design of high performance superalloys [4].

\section{Alloying Vectors}

Alloying vectors were also presented in Fig. 1 and Fig.2. For an individual alloying element, the vector starts at the pure Ni position and ends at the position of a $\mathrm{Ni}-10 \mathrm{~mol} \% \mathrm{M}$ alloy. Needless to say, the vector length increases with increasing composition of $\mathrm{M}$ in the alloy. The vector direction changes simply with the group number of the element in the periodic table. For example, all the 5A group elements, $\mathrm{V}, \mathrm{Nb}$ and $\mathrm{Ta}$, take the nearly same direction. This is also the case for the $4 \mathrm{~A}$ group elements, $\mathrm{Ti}, \mathrm{Zr}$ and $\mathrm{Hf}$ and for the $6 \mathrm{~A}$ group elements, $\mathrm{Cr}, \mathrm{Mo}$ and $\mathrm{W}$. These periodic changes in the directions are simple due to the periodic changes in the respective parameters of Bo and Md with M, as shown in Fig.3. The knowledge of the periodic table of elements is indeed condensed in the two electronic parameters, Bo and Md.

It is also true that the $\gamma^{\prime}$ stabilizing elements such as $\mathrm{Al}, \mathrm{Ti}, \mathrm{V}, \mathrm{Nb}$, Ta take relatively lower $\theta$ angles than the $\gamma$ stabilizing elements such as $\mathrm{Cr}, \mathrm{Mo}, \mathrm{W}, \mathrm{Re}$, as shown in the figure. So, the $\theta$ angle is an indication for the stability of the $\gamma^{\prime}$ phase, and it is related closely to the $\gamma^{\prime}$ volume fraction, as explained later.

A best combination of alloying elements and their amounts in the alloy can be selected readily using these alloying vectors so that the alloy composition falls on the target region in the Bo-Md diagram. For a superalloy, a total vector is defined by the vector sum of each alloying vector, the length of which is proportional to the amount of the element in it. One example is shown in Fig.4 for the TUT92 alloy [4].

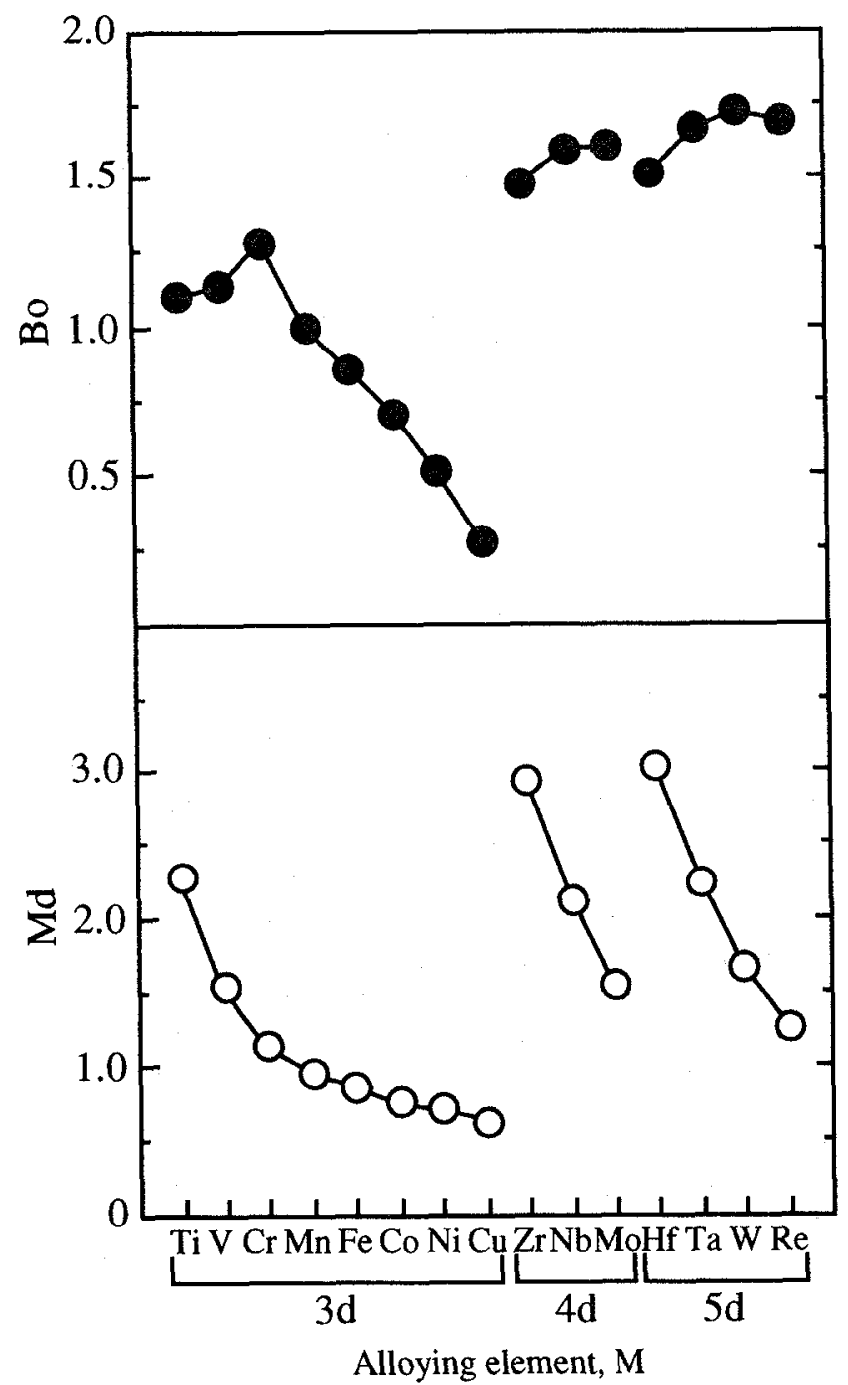

Fig.3. Changes in the Bo and Md values with alloying elements.

\section{$\gamma^{\prime}$ Volume Fraction}

In Fig.4, $\theta$ is defined as the angle between the total vector of TUT 92 and the alloying vector of $\mathrm{Al}$. For any superalloy, the value of $\theta$ can be calculated readily from the $\overline{B o}$ and the $\overline{M d}$ values of the alloy. As shown in Fig.5 [5], they vary approximately linearly with the $y$. volume fraction in the superalloys. Such a relationship holds even in a wide range of the $\gamma^{\prime}$ volume fraction of $20 \%$ to $70 \%$. Using this relationship, the $\gamma^{\prime}$ volumefraction in any multi-components superalloys can be estimated readily from the calculated $\theta$ angle of the total vector. The alloys locating in the target region in Fig.1 or Fig. 2 have about $30^{\circ}$ in $\theta$, indicating that the $\gamma$ ' volume fractions of them are $55-65 \%$. 


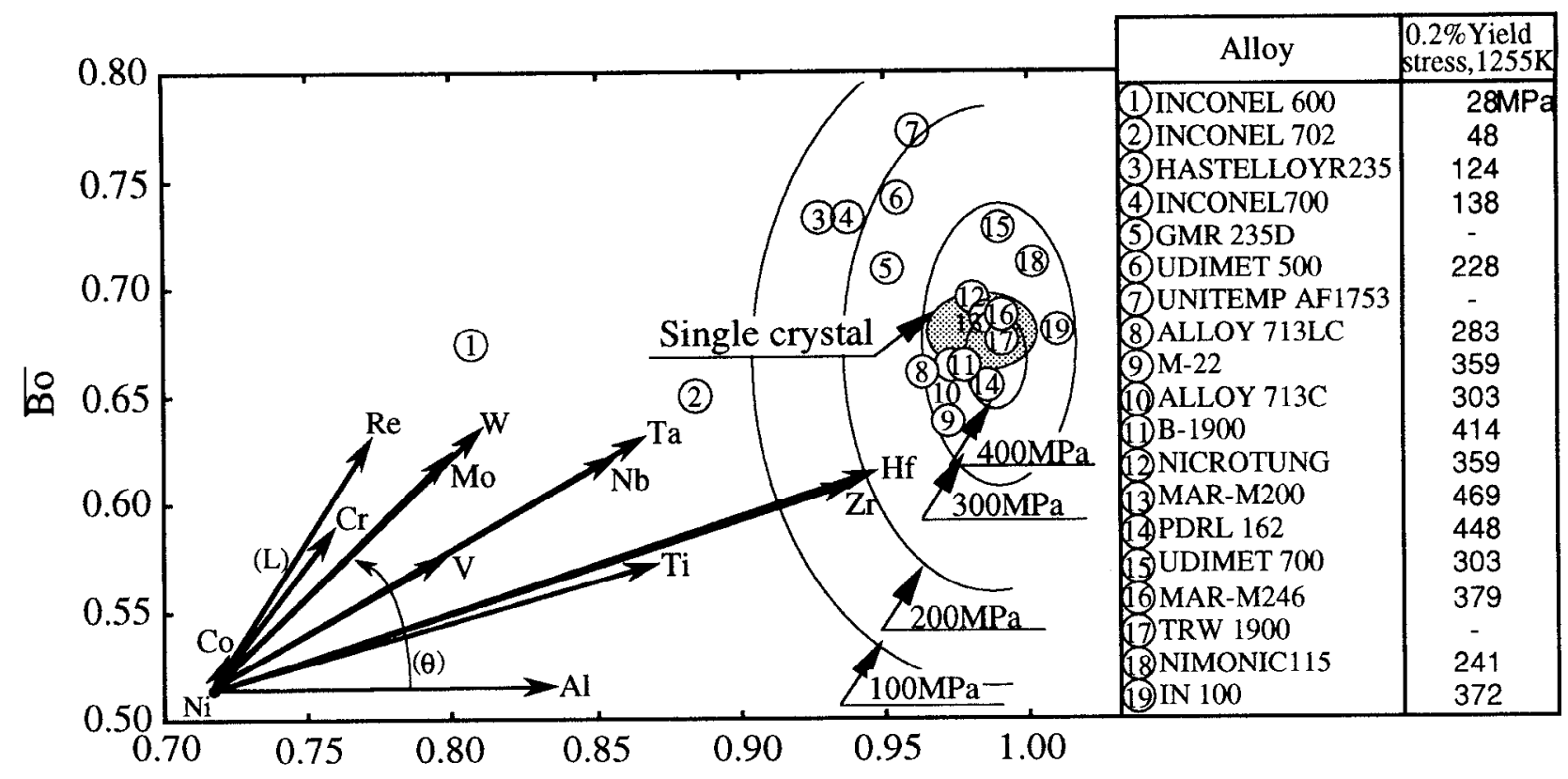

$\overline{\mathrm{Md}}$

Fig. $1 \overline{\mathrm{Bo}}-\overline{\mathrm{Md}}$ diagram showing the locations of conventionally cast superalloys and the contour lines of $0.2 \%$ yield stress. The vectors represent the location of $\mathrm{Ni}-10 \mathrm{~mol} \% \mathrm{M}$ alloys.

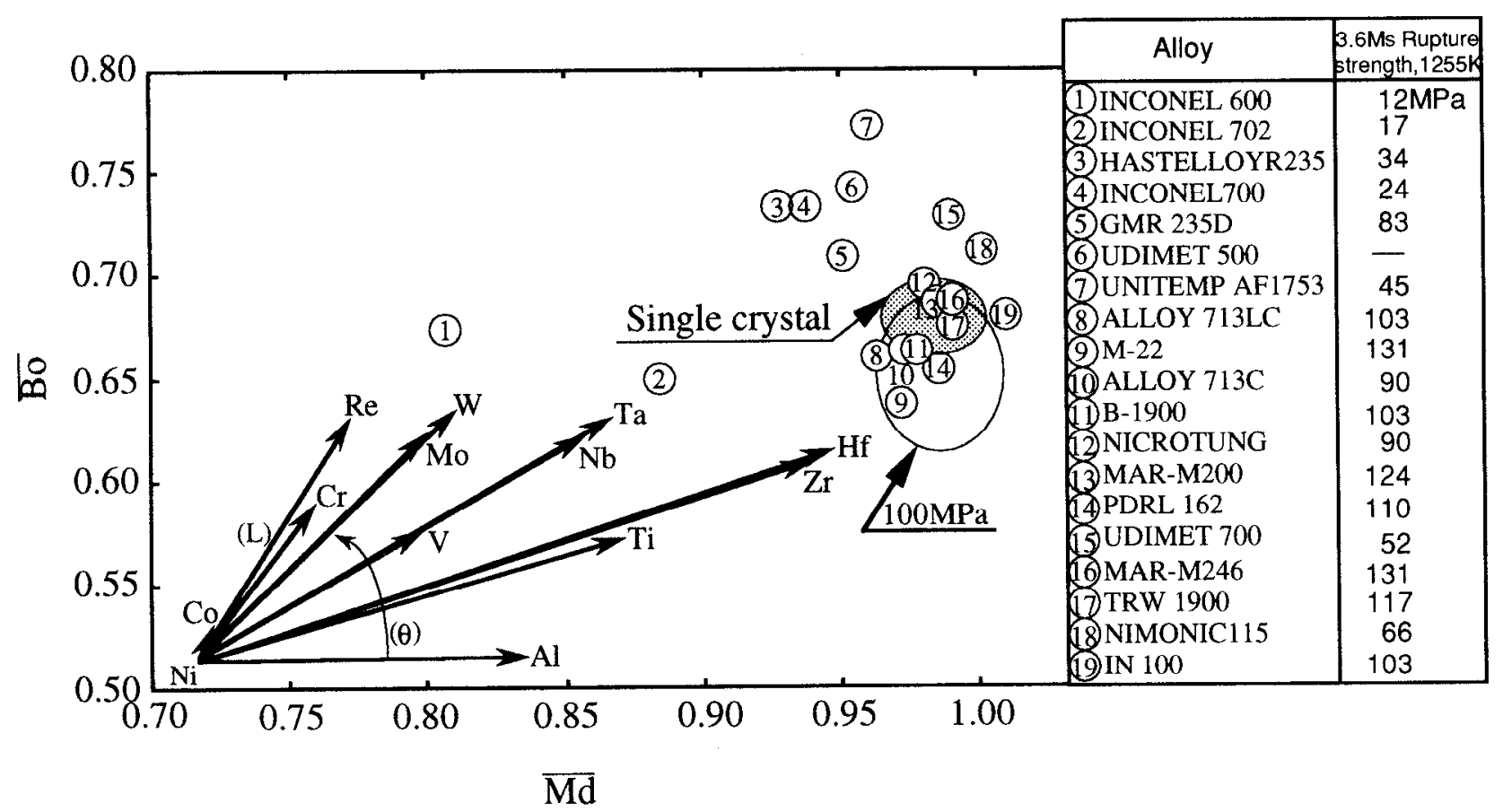

Fig.2. $\overline{\mathrm{Bo}}-\overline{\mathrm{Md}}$ diagram showing the locations of conventional cast superalloys and the contour lines of $3.6 \mathrm{Ms}$ rupture strength. The vectors represent the location of $\mathrm{Ni}-10 \mathrm{~mol} \% \mathrm{M}$ alloys. 


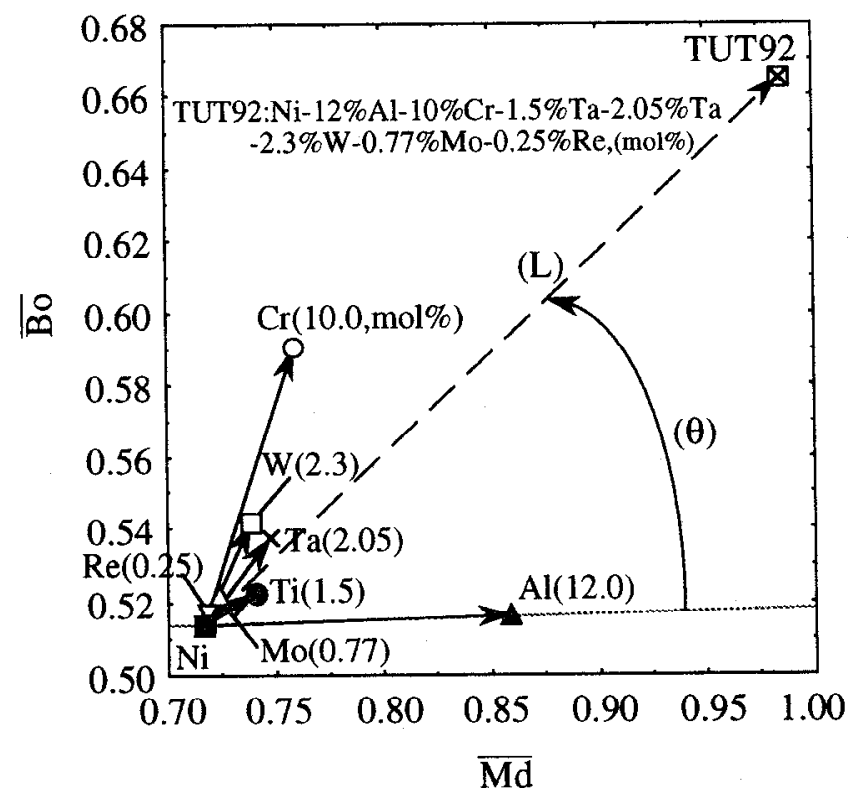

Fig.4. Representation of the alloying vectors for TUT92 alloy in the Bo- $\overline{\mathrm{Md}}$ diagram.

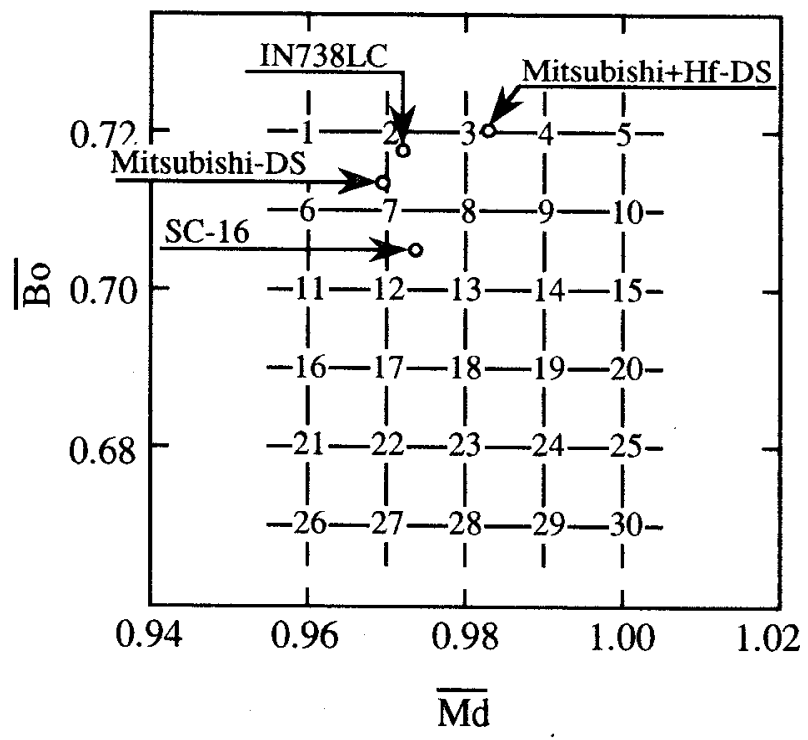

Fig.6. Target region for the design of superalloys in the $\overline{\mathrm{Bo}}-\overline{\mathrm{Md}}$ diagram.

\section{Criteria for Alloy Design}

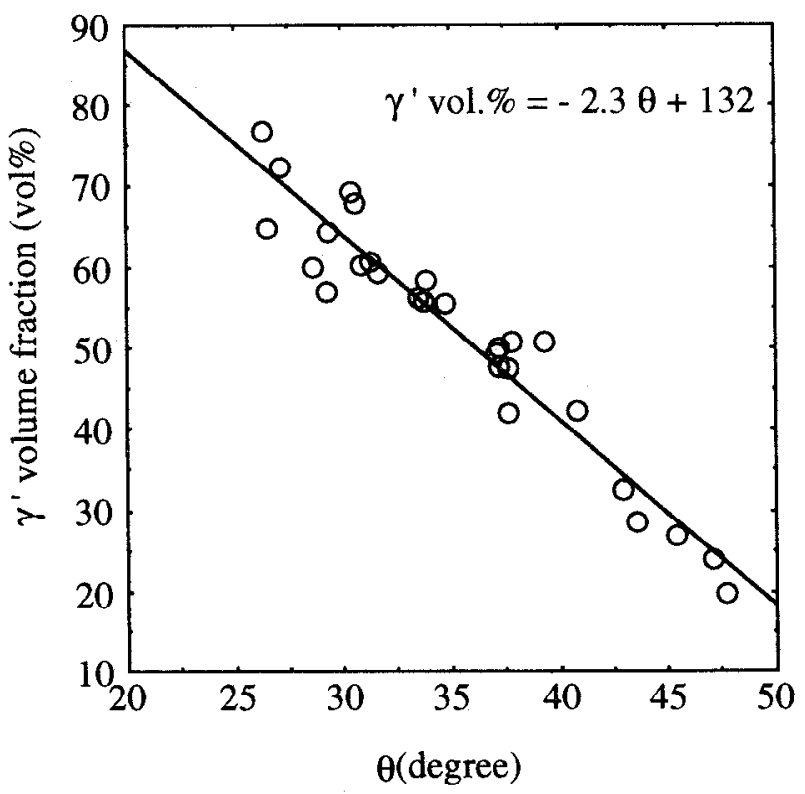

Fig.5. Correlation between the $\gamma^{\prime}$ volume fraction and the parameter, $\theta$, of alloying vectors.
New superalloys were designed using the d-electrons concept together with the following six criteria; (1) containing more than $15 \mathrm{~mol} \% \mathrm{Cr}$ in order to guarantee hot corrosion resistance superior or at least comparable to IN738LC which is a typical hot-corrosion resistant alloy used in corrosive environments, (2) increasing $\mathrm{W}+\mathrm{Mo}+\mathrm{Re}$ contents for strengthening the $\gamma$ phase, (3) increasing the $\gamma^{\prime}$ volume fraction with the aid of the Bo-Md diagram, (4) controlling the $\mathrm{Ta}+\mathrm{Ti}(+\mathrm{Nb}) / \mathrm{Al}$ compositional ratio to be suitable for strengthening the $\gamma^{\prime}$ phase, (5) adjusting the W/Mo compositional ratio to a proper value in view of fabrication conditions, and (6) lowering alloy density calculated by the Hull's regression equation [6].

\section{Calculation of Alloy Compositions}

A suitable combination of alloying elements and their compositions in the alloy should be selected so that the alloy is located inside the target region on the Bo-Md diagram shown in Figs.1 and 2, while holding all the six criteria. Following these fundamental objects in view, the target region was divided into 30 mesh points, as shown in Fig.6. The alloy compositions falling on each mesh point were then calculated following the steps shown in Fig.7. In this calculation, a clearance of the both Md and $\mathrm{Bo}$ values was limited to be within \pm 0.001 for each 


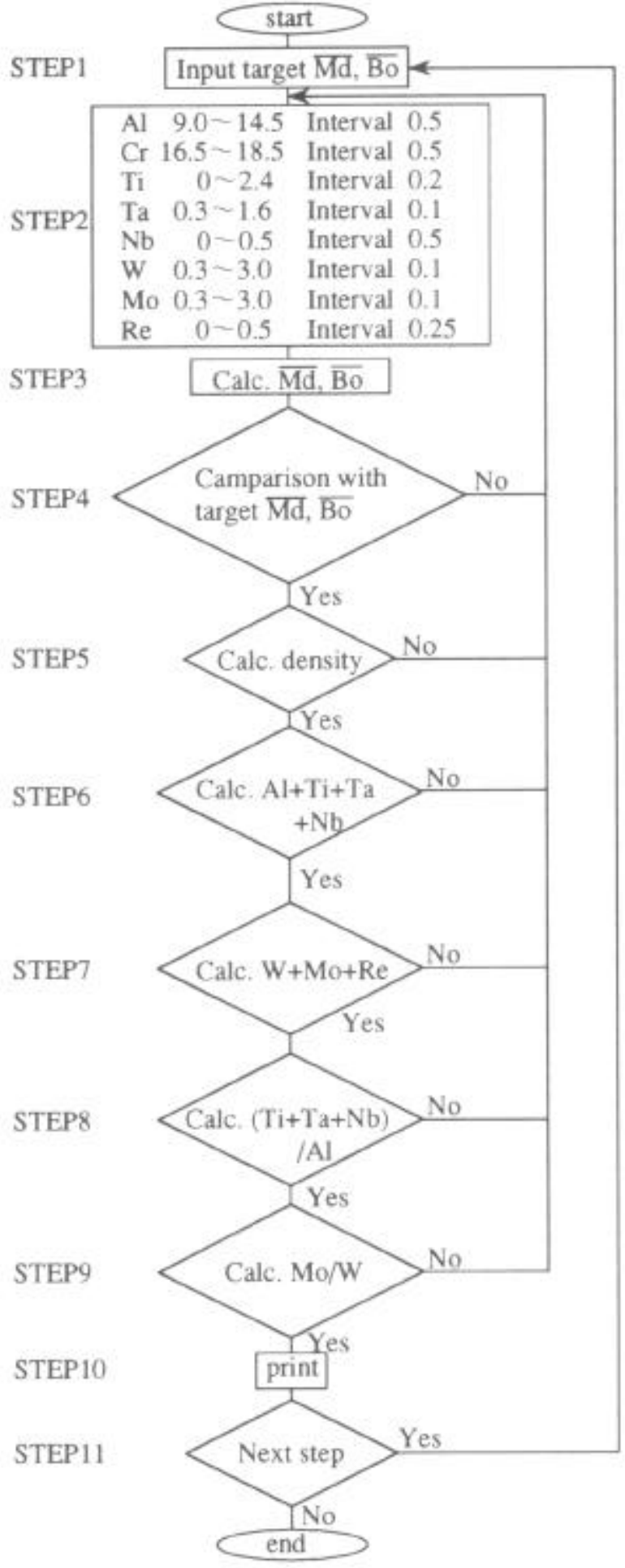

Fig.7. Flow chart for the design of hot-corrosion resistant and high strength nickel-based single crystal superalloys.

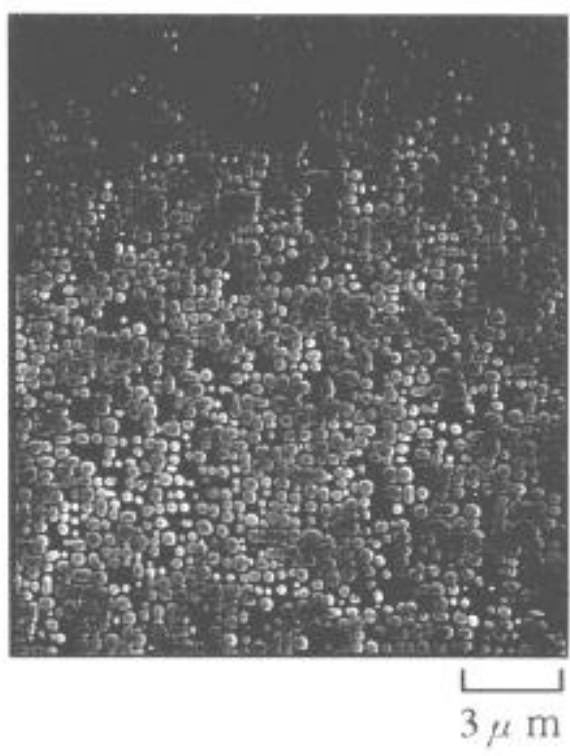

Fig.8. Typical SEM image of designed singlecrystal superalloy, S-5, after the heat treatment.

value which was set primarily at the individual mesh point. The compositional range and the interval used for the calculation were also shown in Fig. 7 for each element in the alloy.

As a result of the calculation, about 20 alloys were obtained as the first candidate alloys. With these alloys preliminary experiments were carried out on the phase stability at $1173 \mathrm{~K}$ for $1.8 \mathrm{Ms}$ ( $500 \mathrm{hrs}$ ) and on the Vickers hardness at elevated temperatures. Nine single-crystal (SC) superalloys were finally selected by counting on these results. Their compositions and the values of the parameters for alloy design are listed in Table 2, together with those values for reference alloys used in this study. The mesh numbers illustrated in Fig.6 and the calculated $\gamma^{\prime}$ volume fraction are also listed in the table.

The DS alloys were designed in the same way as the $\mathrm{SC}$ alloys, except for the calculation range of $\mathrm{Cr}$ content. That was set to be $15.0 \sim 18.5 \mathrm{~mol} \%$ for the DS alloys. At first, alloy compositions were obtained by the calculation without involving any grain-boundary strengthening elements, and then six directionally solidified(DS) alloys were designed simply by adding a small amount of $\mathrm{Hf}$ into them, but compensating a certain amount of alloying elements so that the alloy is still located well inside the target region.

A series of experiments was carried out in order to evaluate the properties of these designed alloys. 
Table 2. Nominal compositions of the designed nickel-based alloys and reference alloys ( $\mathrm{mol} \%$ ), and various parameters to characterize the alloys.

\begin{tabular}{|c|c|c|c|c|c|c|c|c|c|c|c|c|c|c|}
\hline & Alloy & $\mathrm{Cr}$ & $\mathrm{Al}$ & $\mathrm{Ti}$ & $\mathrm{Ta}$ & $\mathrm{Nb}$ & W & Mo & $\operatorname{Re}$ & $\mathrm{Ni}$ & Co & B & $\mathrm{Zr}$ & $\mathrm{Hf}$ \\
\hline \multirow{9}{*}{ 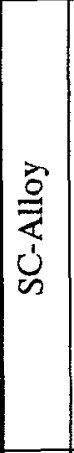 } & $S-1$ & 17.00 & 9.50 & 0.60 & 1.50 & 0.50 & 1.50 & 1.80 & - & Bal. & - & - & - & - \\
\hline & S-2 & 17.50 & 10.00 & 1.20 & 1.20 & 0.50 & 1.20 & 1.80 & - & Bal. & - & - & - & - \\
\hline & $S-3$ & 17.00 & 11.002 & 2.00 & 0.60 & 0.50 & 1.20 & 1.40 & - & Bal. & - & - & - & - \\
\hline & $S-4$ & 17.00 & 11.50 & 2.40 & 0.60 & 0.50 & 1.20 & 1.20 & - & Bal. & - & - & - & - \\
\hline & S-5 & 17.50 & 11.002 & 2.40 & 0.30 & 0.50 & 1.60 & 1.60 & - & Bal. & - & - & - & - \\
\hline & S-6 & 17.00 & 10.50 & 1.60 & 0.60 & 0.50 & 1.30 & 1.60 & - & Bal. & - & - & - & - \\
\hline & SR-1 & 16.50 & 12.00 & 1.80 & 0.80 & 0.50 & .1 .20 & 1.40 & 0.25 & Bal. & - & - & - & - \\
\hline & SR-2 & 17.50 & 11.00 & 1.10 & 1.40 & 0.50 & 1.20 & 1.30 & 0.25 & Bal. & - & - & - & - \\
\hline & SR-3 & 17.00 & 10.50 & 1.60 & 0.70 & 0.50 & 1.20 & 1.30 & 0.25 & Bal. & - & - & - & - \\
\hline \multirow{6}{*}{ 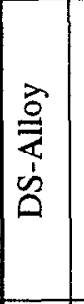 } & D-1 & 16.50 & 10.77 & 1.96 & 1.57 & - & 1.60 & 1.60 & - & Bal. & - & - & - & 0.30 \\
\hline & D-2 & 17.50 & 10.77 & 2.35 & 0.78 & - & 1.60 & 1.60 & - & Bal. & - & - & - & 0.30 \\
\hline & D-3 & 15.00 & 11.76 & 2.35 & 0.78 & - & 1.20 & 2.00 & - & Bal. & - & - & - & 0.30 \\
\hline & DR-1 & 15.00 & 9.27 & 1.17 & 1.56 & - & 1.20 & 1.20 & 0.50 & Bal. & - & - & - & 0.30 \\
\hline & DR-2 & 15.00 & 13.72 & - & 0.78 & - & 0.80 & 1.60 & 0.25 & Bal. & - & - & - & 0.30 \\
\hline & DR-3 & 16.00 & 10.77 & 1.57 & 1.96 & - & 1.60 & 1.60 & 0.25 & Bal. & - & - & - & 0.30 \\
\hline \multirow{5}{*}{ 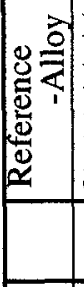 } & IN738LC & 17.50 & 7.20 & 4.00 & 0.53 & 0.55 & 0.80 & 1.00 & - & Bal. & $8.20 \quad 0.5$ & $52 \quad 0.05$ & $5 \quad 0.03$ & - \\
\hline & Mitsubishi-DS & 17.24 & 7.34 & 3.98 & 0.51 & 0.40 & 0.82 & 0.99 & - & Bal. & $8.07 \quad 0.4$ & $47 \quad 0.05$ & $158 \quad 0.02$ & - \\
\hline & Mitsubishi+Hf-DS & 17.40 & 7.41 & 4.02 & 0.52 & 0.40 & 0.83 & 1.00 & - & Bal. & $8.14 \quad 0.4$ & $48 \quad 0.05$ & 1580.03 & $\begin{array}{ll}3 & 0.45\end{array}$ \\
\hline & SC-16 & 17.46 & 7.36 & 4.15 & 1.10 & - & - & 1.77 & - & Bal. & - & - & - & - \\
\hline & Alloy & $\overline{\mathrm{Md}}$ & $\overline{\mathrm{Bo}}$ & \multicolumn{2}{|c|}{$\mid \begin{array}{c}\text { Density } \\
\left(\mathrm{g} / \mathrm{mm}^{3}\right)\end{array}$} & \multicolumn{2}{|c|}{$\begin{array}{r}\mathrm{Al}+\mathrm{Ti}+\mathrm{Ta}+\mathrm{Nb} \\
(\mathrm{mol} \%) \\
\end{array}$} & \multicolumn{2}{|c|}{$\begin{array}{r}\mathrm{W}+\mathrm{Mo}+\mathrm{Re} \\
(\mathrm{mol} \%)\end{array}$} & \multicolumn{2}{|c|}{$(\mathrm{Ti}+\mathrm{Ta}+\mathrm{Nb}) / \mathrm{Al}$} & $\mathrm{Mo} / \mathrm{W}$ & $\begin{array}{c}\text { mesh } \\
\text { No. }\end{array}$ & $\begin{array}{c}\gamma^{\prime} \\
\text { (vol.\%) } \\
\end{array}$ \\
\hline \multirow{9}{*}{ 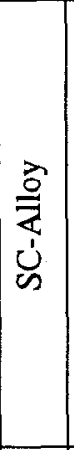 } & S-1 & 0.9696 & 0.7099 & \multirow{2}{*}{\multicolumn{2}{|c|}{$\begin{array}{l}8.43 \\
8.29\end{array}$}} & \multicolumn{2}{|c|}{12.10} & \multicolumn{2}{|c|}{3.30} & \multicolumn{2}{|r|}{0.27} & 1.20 & 7 & 46 \\
\hline & $S-2$ & 0.9797 & 0.7102 & & & \multicolumn{2}{|c|}{12.90} & \multicolumn{2}{|c|}{3.00} & \multicolumn{2}{|r|}{0.29} & 1.50 & 8 & 49 \\
\hline & $\mathrm{S}-3$ & 0.9894 & 0.6999 & \multicolumn{2}{|c|}{8.14} & \multicolumn{2}{|c|}{14.10} & \multicolumn{2}{|c|}{2.60} & \multicolumn{2}{|r|}{0.28} & 1.17 & 14 & 54 \\
\hline & S-4 & 0.9999 & 0.7002 & \multicolumn{2}{|c|}{8.11} & \multicolumn{2}{|c|}{15.00} & \multicolumn{2}{|c|}{2.40} & & 0.30 & 1.00 & 15 & 56 \\
\hline & S-5 & 0.9987 & 0.7097 & 8.1 & & 14.2 & & 3.21 & & & 0.29 & 1.00 & 10 & 53 \\
\hline & $S-6$ & 0.9799 & 0.7009 & 8.1 & 19 & 13.2 & & 2.90 & & & 0.26 & 1.23 & 13 & 52 \\
\hline & SR-1 & 1.0004 & 0.7004 & 8.1 & 16 & 15. & & 2.8 & & & 0.26 & 1.17 & 15 & 56 \\
\hline & SR-2 & 0.9902 & 0.7096 & 8.3 & 30 & 14. & & 2.7 & & & 0.27 & 1.08 & 9 & 51 \\
\hline & SR-3 & 0.9793 & 0.7005 & 8.2 & 23 & 13. & & 2.75 & & & 0.27 & 1.08 & 13 & 52 \\
\hline & D-1 & 1.0039 & 0.7117 & 8.3 & 39 & 14. & & 3.20 & & & 0.33 & 1.00 & 10 & 53 \\
\hline | & D-2 & 1.0023 & 0.7125 & 8.2 & 26 & 13. & & 3.20 & & & 0.29 & 1.00 & 10 & 53 \\
\hline 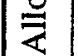 & D-3 & 1.0030 & 0.6931 & 8.1 & 18 & 14.8 & & 3.20 & & & 0.27 & 1.70 & 20 & 60 \\
\hline$\dot{\check{g}}$ & DR-1 & 0.9630 & 0.6919 & 8.5 & 54 & 12. & & 2.90 & & & 0.29 & 1.00 & 16 & 50 \\
\hline & $\mathrm{DR}-2$ & 0.9839 & 0.6735 & 8.0 & 08 & 14. & & 2.62 & & & 0.06 & 2.00 & 28 & 62 \\
\hline & DR-3 & 1.0030 & 0.7131 & & 49 & 14. & & 3.45 & & & 0.33 & 1.00 & 10 & 53 \\
\hline 흐 & IN738LC & 0.9719 & 0.7177 & 8.2 & 21 & 11. & & 1.80 & & & 0.63 & 1.25 & 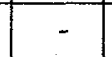 & 44 \\
\hline $\mid$ & Mitsubishi-DS & 0.9696 & 0.7136 & 8.2 & 21 & 11.8 & & 1.13 & & & 0.61 & 0.38 & - & 46 \\
\hline 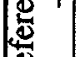 & Mitsubishi+Hf-DS & 0.9828 & 0.7202 & 8.2 & 25 & 11. & & 1.83 & & & 0.61 & 1.20 & - & 46 \\
\hline$\approx$ & SC-16 & 0.9741 & 0.7052 & & 21 & 12. & & 1.77 & & & 0.71 & - & - & 46 \\
\hline
\end{tabular}




\section{Experimental Procedure}

All the designed SC alloys had a two-phase structure consisting of the $\gamma$ phase and the $\gamma^{\prime}$ phase, and any other phases did not exist. In fact, even the $\gamma+\gamma$ ' eutectic phase did not form in them. The typical morphology of the $\gamma$ ' phase is shown in Fig.8. Subsequently performed were two kinds of hot-corrosion tests and a creep-rupture test. Both the SC specimens and the DS specimens were prepared by the Bridgman method and supplied to the creep-rupture test. But polycrystalline specimens prepared by arc melting were employed for the hot-corrosion tests. In this study, SC-16 [7], IN738LC and Mitsubishi-DS alloys [8] were selected as the reference alloys for the purpose of property evaluation of the designed alloys.

All the alloys were prepared from raw materials of $99.95 \% \mathrm{Ni}, 99.99 \% \mathrm{Al}, 99.98 \% \mathrm{Cr}, 99.8 \% \mathrm{Ti}, 99.5 \% \mathrm{Ta}$, $99.9 \% \mathrm{Nb}, 88.87 \% \mathrm{~W}, 99.96 \% \mathrm{Re}$ and $99.5 \% \mathrm{Mo}$. They were heat treated as follows;

(i) for hot-corrosion tests: solution heat treatment : $1473 \mathrm{~K} / 86.4 \mathrm{ks} / \mathrm{A} . \mathrm{C}$. aging : $1273 \mathrm{~K} / 57.6 \mathrm{ks} / \mathrm{A} . \mathrm{C} .+1123 \mathrm{~K} / 72 \mathrm{ks} / \mathrm{A} . \mathrm{C}$.

(ii) for crecp test:

$\mathrm{SC}$ alloys: solution heat treatment : $1573 \mathrm{~K} / 14.4 \mathrm{ks} / \mathrm{A} . \mathrm{C}$. aging : $1273 \mathrm{~K} / 57.6 \mathrm{ks} / \mathrm{A} . \mathrm{C} .+1123 \mathrm{~K} / 72 \mathrm{ks} / \mathrm{A} . \mathrm{C}$.

DS alloys: solution heat treatment : $1498 \mathrm{~K} / 7.2 \mathrm{ks} / \mathrm{A} . \mathrm{C}$. aging : $1373 \mathrm{~K} / 14.4 \mathrm{ks} / \mathrm{A} . \mathrm{C} .+1143 \mathrm{~K} / 72 \mathrm{ks} / \mathrm{A} . \mathrm{C}$.

\section{Hot-Corrosion Test}

Two kinds of methods were employed for the hotcorrosion test. One is the coating test, and the other is the immersion test. In both tests, hot corrosion resistance was evaluated by the amount of weight loss of the specimen after descaling the corrosion products on the surface.

Coating Method : The surface of the specimen with $2 \times 5 \times 10 \mathrm{~mm}$ in size was coated with a solid solution of $\mathrm{Na}_{2} \mathrm{SO}_{4}-25 \mathrm{~mol} \% \mathrm{NaCl}$ salt by $0.2 \mathrm{~kg} / \mathrm{m}^{2}$, and then the specimen was inserted into a tube furnace for exposure to the static air at $1173 \mathrm{~K}$ for $72 \mathrm{ks}$ ( $20 \mathrm{hrs})$. After the exposure, corrosion products on the specimen surface were descaled with a brass-wire brush after boiling in a $18 \mathrm{wt} \% \mathrm{NaOH}-5 \mathrm{wt} \% \mathrm{KMnO}_{4}$ aqueous solution for $1.8 \mathrm{ks}$, followed by boiling in a $10 \mathrm{wt} \%\left(\mathrm{NH}_{4}\right)_{2} \mathrm{HC}_{6} \mathrm{H}_{5} \mathrm{O}_{7}$ aqueous solution for $1.2 \mathrm{ks}$.

Immersion Method : $\mathrm{A} \mathrm{Na}_{2} \mathrm{SO}_{4}-25$ mass $\% \mathrm{NaCl}$ solution of $45 \mathrm{~g}$ was melted in a high purity alumina crucible, and then each specimen with $5 \times 5 \times 20 \mathrm{~mm}$ in size was immersed into the solution at $1173 \mathrm{~K}$ for $10.8 \mathrm{ks}$. After the immersion, corrosion products on the specimen surface were descaled in the same way as mentioned above.

\section{Creep-Rupture Test}

For the designed SC alloys and a reference alloy, SC-16 [7], creep-rupture tests were carried out using the single-crystal specimens at $1223 \mathrm{~K}$ under a constant load of $200 \mathrm{MPa}$. On the other hand, for the designed DS alloys and two reference alloys, Mitubishi-DS and Mitubishi+Hf-DS [8], the tests were performed using directionally solidified columnar-crystal specimens at $1123 \mathrm{~K}$ under a constant load of $264.6 \mathrm{MPa}$. For both the SC and the DS specimens, gauge length and gauge diameter of the test piece were $20 \mathrm{~mm}$ and $4 \mathrm{~mm}$, respectively.

\section{Properties of Designed Alloys}

\section{SC Alloys}

The results of creep-rupture tests are shown in Fig.9. In this figure, the present result on SC-16 was slightly different from that reported by Khan et al. [7], probably due to the difference in the specimen preparation between them.

All the designed SC alloys were superior in the rupture life to SC-16. In particular, SR-3 alloy showed about three times longer rupture-life than SC-16. On the other hand, there was a tendency for the elongation to become shorter for the designed alloys than for SC-16. But it is considered that the magnitude of the elongation for the designed alloys is still large enough for the practical use.

The results of hot-corrosion tests are shown in Fig.10. The weight changes for the designed alloys were comparable to those for two reference alloys, SC-16 and IN738LC. Therefore, it is concluded that the designed $\mathrm{SC}$ alloys have high hot-corrosion resistance as well as superior creep properties.

The $\gamma^{\prime}$ volume fraction is higher in the designed alloys than in the reference alloys, as shown in Table 2. It has been generally accepted that hot-corrosion resistance decreases with increasing $\gamma^{\prime}$ volume fraction, because c.f the lower hot-corrosion resistance of the $\gamma$ ' phase than the $\gamma$ phase. However, it has been found recently that the hot corrosion resistance is nearly independent of the $\gamma^{\prime}$ volume fraction as long as alloy compositions vary along a $\gamma-\gamma^{\prime}$ tie line in the phase diagram [9]. This is interpreted as due to the formation of a new single phase region underneath the corrosion products on the surface in the course of corrosion time. This phase region is different in the composition from hoth the $\gamma$ and $\gamma$ ' phases. The composition is nearly constant irrespective of the alloys as long as the alloy compositions lie on a $\gamma-\gamma^{\prime}$ tie line [9] This means that hot-corrosion resistance is associated mainly with the composition of the single phase region formed undernealh the corrosion products. However, it is also true that the composition of the single phase region varies when alloy compositions do not lie on the same tie line. In such a case, the hot-corrosion resistance changes largely with the alloy compositions. 


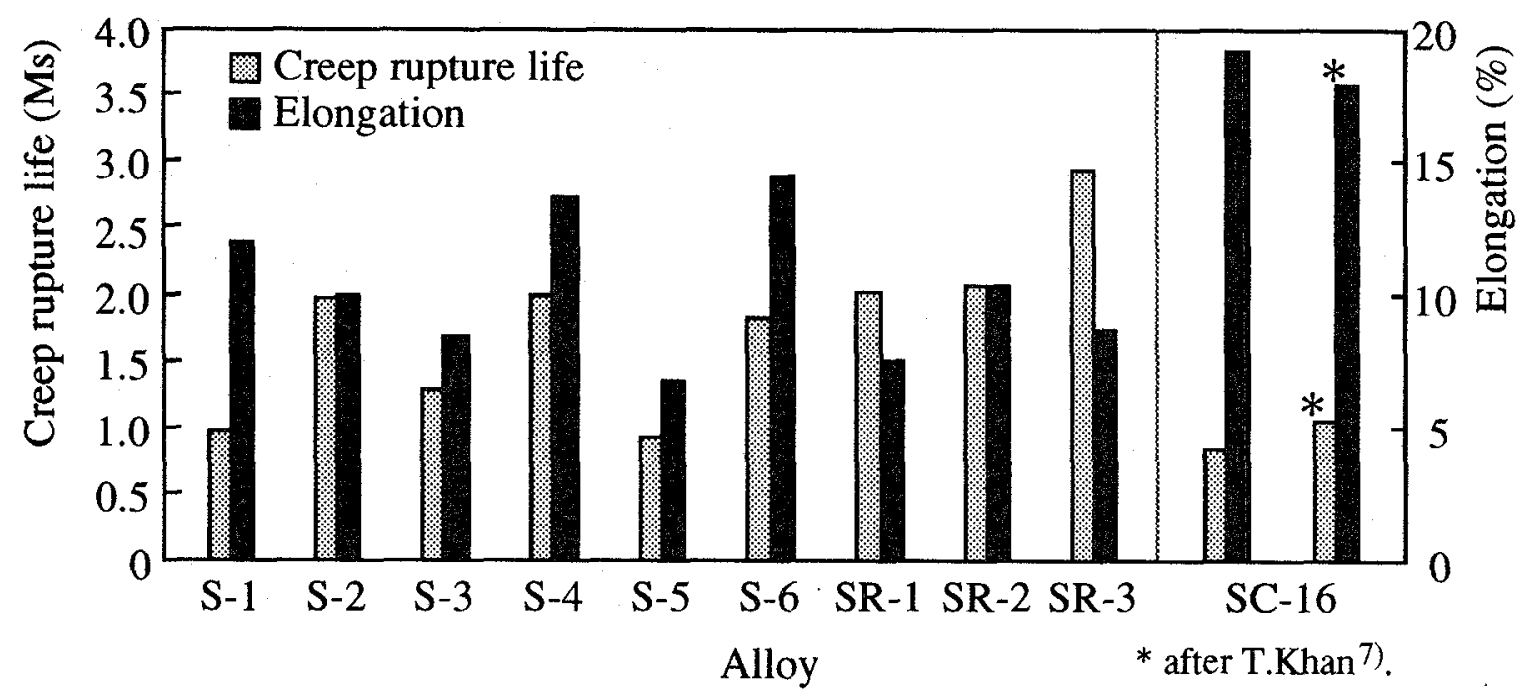

Fig.9. Results of the creep rupture life and the elongation for the designed singlecrystal alloys and the reference alloy.

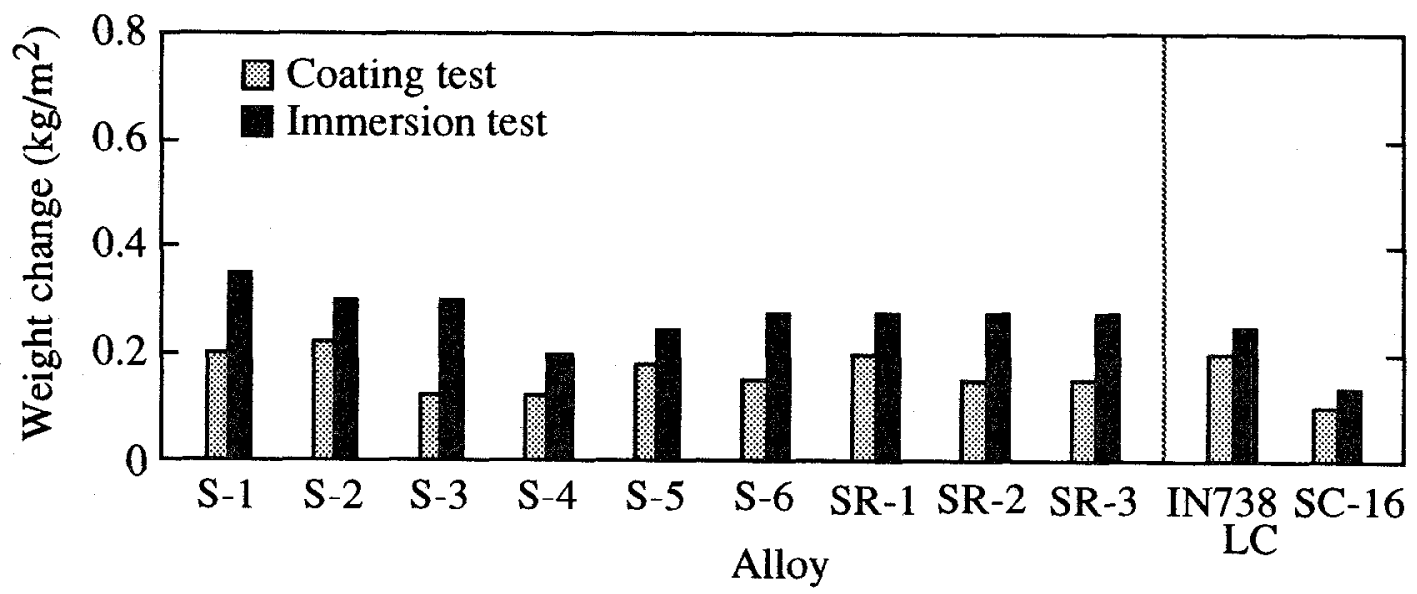

Fig.10. Weight changes of the designed single-crystal alloys and the reference alloys. 


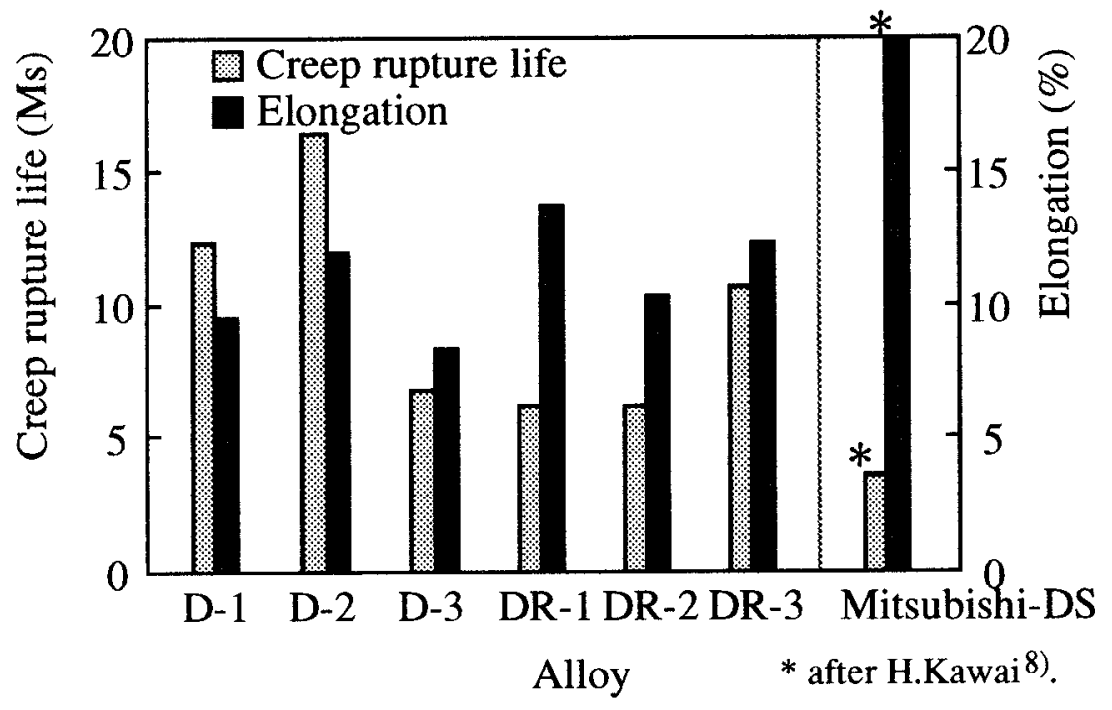

Fig.11. Results of the creep rupture life and the elongation for the designed DS alloys and the reference alloy.

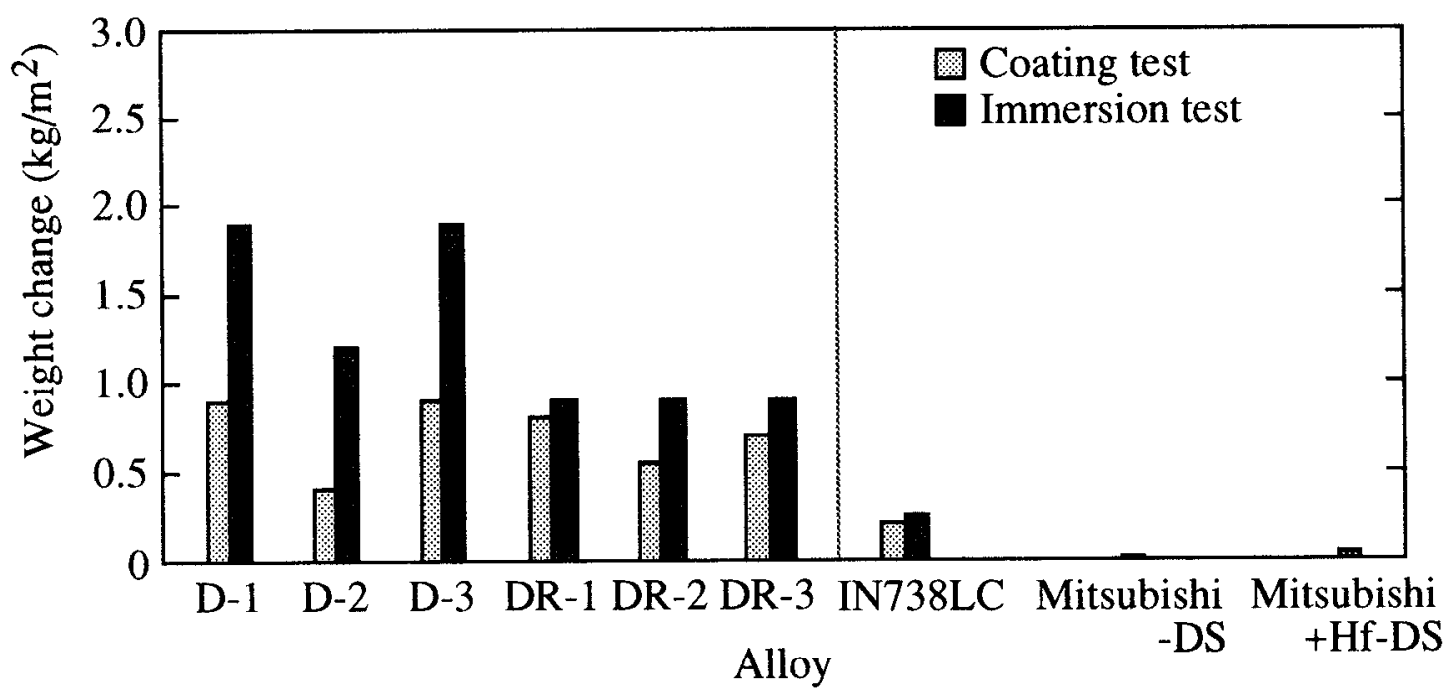

Fig.12. Weight changes of the designed DS alloys and the reference alloys. 


\section{DS Alloys}

The creep-rupture properties of the designed DS alloys are shown in Fig.11, together with the result of a reference alloy, Mitsubishi-DS. The designed alloys showed more than 2 times longer rupture life than the reference alloy. In particular, D-2 alloy showed about 5 times longer rupture life. As is similar to the SC alloys, the designed DS alloys exhibited the shorter elongation than the reference alloy. But still it is large enough for the practical use.

Fig. 12 shows the results of hot-corrosion resistance of the designed DS alloys and three reference alloys. The corrosion results depended on the method for the corrosion test. In case of the coating test, there were not significant differences in the corrosion resistance among the designed alloys and the reference alloys. However, the differences became remarkable in the immersion test. The corrosion resistance was poorer for the designed alloys than for the reference alloys. The reason for the poor resistance of the designed alloys is not unknown. But the addition of $\mathrm{Hf}$, which is a strengthening element of the grain boundaries, may lead to the poor hot-corrosion resistance, since the Hf-free SC alloys showed excellent hot-corrosion resistance, as shown in Fig.10. The hotcorrosion resistance of the DS alloys will be improved by controlling the alloying of grain-boundary strengthening elements in a proper manner.

\section{Conclusion}

It is concluded that the present molecular orbital approach is very useful for the design and development of nickel-based superalloys for the applications to industrial turbines.

\section{Acknowledgement}

This research was supported in part by Grant-in Aid for Scientific Research from the Ministry of Education, Science and Culture of Japan.

\section{References}

1. N.Yukawa, M.Morinaga, Y.Murata, H.Ezaki and S.Inoue, " High Performance Single Crystal Superalloys Developed by the d-Electrons Concept ", Proc. of 6th Inter. Symp. on Superalloys, ed. by D.N.Duhlet al., The Metallurgical Society, Inc., (1988), 225-234.

2. K.Matsugi, R.Yokoyama, Y.Murata, M.Morinaga and N.Yukawa," High Temperature Properties of Single Crystal Superalloys Optimized by an Electron Theory ",
Proc. of 4th Int. Conf. on High Temperature Materials for Power Eng. 1990, ed. by E.Bachelet et al., Kluwer Academic Publishers, Dordrecht (Netherlands), (1990), $1251-1260$.

3. M.Morinaga, N.Yukawa and H.Adachi, " Alloying Effect on the Electronic Structure of $\mathrm{Ni}_{3} \mathrm{Al}\left(\gamma^{\prime}\right)$ ", J. Phys. Soc. Japan, 53(2)(1984), 653-663.

4. K.Matsugi, Y.Murata, M.Morinaga and N.Yukawa, " Realistic Advancement for Nickel-based Single Crystal Superalloys by the d-Electrons Concept", Proc. of the 7th Inter. Symp. on Superalloys, Ed. by S.D. Antolovich et a., TMS, (1992), 307-316.

5. Y.Murata, S.Miyazaki and M.Morinaga, " Evaluation of the Partitioning Ratios of Alloying Elements in NickelBased Superalloys by the d-Electrons Parameters", Materials for Advanced Power Engineering 1994, ed. by D.Coutsouradis et al., Kluwer Academic Publishers, Dordrecht (Netherlands), (1994), 909-918.

6. F.C. Hull, " Estimating Alloy Density ", Metal Progress, (1996), Nov., 139-140.

7. T.Khan and P.Caron, " Development of a New Single Crystal Superalloy for Industrial Gas Turbine Blades ", Proc. of 4th Int. Conf. on High Temperature Materials for Power Eng. 1990, ed. by E.Bachelet et al., Kluwer Academic Publishers, Dordrecht (Netherlands), (1990), 1261-1270.

8. H.Kawai, I.Okada, I.Tsuji and K.Takahashi, " Development of Directionally Solidified Blade for Industrial Gas Turbine ", Report of the 123rd Cumuilte on Heat-Resisting Metals and Alloys, Japan Soc. for the Promotion of Sci., 34(2)(1993), 223-228.

9. S.Miyazaki, Y.Kusunoki, Y.Murata and M.Morinaga, " A $\gamma$ ' Phase Volume-fraction at Effect on the Hot Corrosion Resistance of Ni-based Superalloys Varying the Compositions Along a $\gamma-\gamma$ ' Tie Line ", 'Tetsu-to-Hagane, 81,(12),(1995), 1168-1173. 